\title{
Study on Fatigue Life of Heat-treated Aluminium alloy coated with Castor oil.
}

\author{
A.Sivasubramanian ${ }^{1, *}$, T.S.Kirubasankar ${ }^{2}$, and S. Vinoth kumar ${ }^{3}$ \\ ${ }^{1}$ Department of Mechanical Engineering, VSB Engineering College. Karur \\ ${ }^{2}$ Department of Mechanical Engineering, VSB Engineering College. Karur \\ ${ }^{3}$ Department of Mechanical Engineering, VSB Engineering College. Karur
}

\begin{abstract}
This paper involves the study of fatigue life of coated aluminium alloy Al 7075-T651 that is heat-treated under $100 \mathrm{oC}$ soaked in castor oil for three days. The specimen after heat treatment is subjected to fatigue test using rotary bending machine for number of cycles to fail under cyclic load of $15 \mathrm{kgf}, 25 \mathrm{Kgf}$, and 50kgf.The life of the specimen is found and compared with uncoated specimen and improved life in number of cycle is noticed. The crack propagation and its type is analysed using scanning electron microscope for knowing the point of fracture and its initiation to failure.
\end{abstract}

\section{Introduction}

Aluminium alloys are extensively used material in the field of aerospace and engineering. The use of Aluminium alloy is greatly enhanced due to its good weight to strength property. Since the specific gravity of aluminium is nearly $2.7 \mathrm{~g} / \mathrm{cc}$, the aluminium alloy has a great role in aircraft sturrctues.Aluminium alloys are used in automobiles, aircrafts and in most of the manufacturing industries. The property such as non-heat treatable, good hardness, corrosion resistance and good thermal conductivity and electrical conductivity [1].

The fatigue life of aluminium plays a vital role in aircraft applications. The fatigue resistance can improve the life of the material and prevents fracture of components at early stages. The life of the component is greatly improved by coating which in turn due to adhesion improves the fatigue toughness of the material.

There are many coating techniques, which were proven more advantageous but require lot of preparatory work on the material to it coated [2]. The deposition rate, adhesion property, chemical treatment is to be taken into consideration for improving the life of the material [3].

The mechanical property of the material is shown and it helps in knowing the important factors, which decided the application of the material in the field of Aeronautics, automobile.etc. The chemical composition also gives an idea on how the material would react to the environmental effects in which it is applied [4].

Table 1. Composition of A17075-T651.

\begin{tabular}{|l|c|}
\hline Compounds & \% by weight \\
\hline Aluminium & $87-91.4$ \\
\hline Zinc & $5.1-6.1$ \\
\hline Magnesium & $2.1-2.9$ \\
\hline Copper & $1.2-2.0$ \\
\hline Iron & $0.5 \mathrm{Max}$ \\
\hline Silicon & $0.4 \mathrm{Max}$ \\
\hline Manganese & $0.3 \mathrm{Max}$ \\
\hline Chromium & $0.18-0.28$ \\
\hline Titanium & $0.2 \mathrm{Max}$ \\
\hline
\end{tabular}

Table2. Mechanical Properties of A17075-T651.

\begin{tabular}{|l|c|c|}
\hline Properties & Value & Units \\
\hline Density & 2.81 & $\mathrm{~g} / \mathrm{cc}$ \\
\hline $\begin{array}{l}\text { Modules of } \\
\text { Elasticity }\end{array}$ & 71.7 & $\mathrm{GPa}$ \\
\hline Poison Ratio & 0.33 & $\mathrm{MPa}$ \\
\hline $\begin{array}{l}\text { Ultimate } \\
\text { Tensile } \\
\text { Strength }\end{array}$ & 572 & $\mathrm{MPa}$ \\
\hline $\begin{array}{l}\text { Yield } \\
\text { Strength }\end{array}$ & 503 & $\mathrm{MPa}$ \\
\hline $\begin{array}{l}\text { Fatigue } \\
\text { Strength }\end{array}$ & 159 & $\mathrm{BHN}$ \\
\hline $\begin{array}{l}\text { Brinell } \\
\text { Hardness }\end{array}$ & 150 & $\mathrm{GPa}$ \\
\hline $\begin{array}{l}\text { Shear } \\
\text { Modulus }\end{array}$ & 26.9 & \\
\hline
\end{tabular}

\footnotetext{
Corresponding author: sivnay123@gmail.com
} 


\section{Experimental Procedure}

The fatigue test is carried out in a standard rotary bending test machine. The specimen is made as per standard requirement and the specimen is prepared for coating before testing. The coating procedure is done in such a way that the specimen is dipped in castor coil at normal room temperature around 32 to 36 degree Celsius for 6 days and then the specimen is heated in an oven at constant temperature of 100 degree Celsius for 20 mins. The oil has high density and due to heating the surface of the material is distracted and oil get adhered to the surface resulting in a coating.

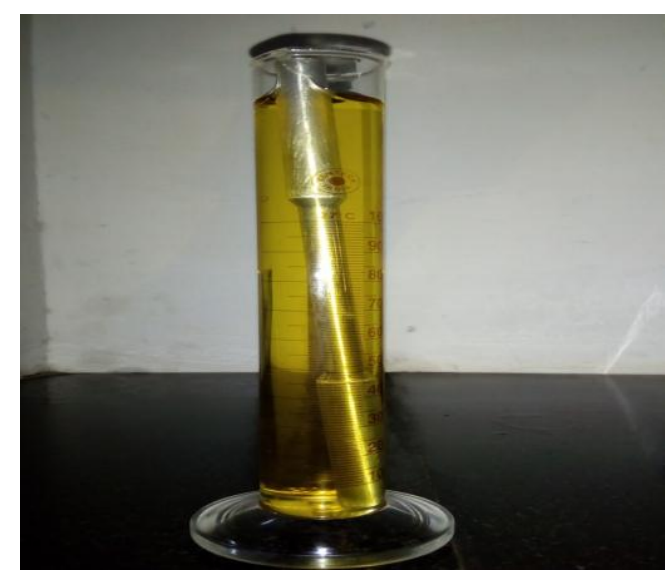

Fig. 1. Fatigue specimen dipped in Oil

The heat treated coated sample is subjected to fatigue test on the rotary bending machine for given load of $25 \mathrm{kgf}, 50 \mathrm{kgf}$ and $75 \mathrm{kgf}$. The number of cycles until the failure is noted for the samples under different loading conditions. Similarly, the same procedure is repeated for uncoated specimen and cycles for failure are noted. The number of cycles for coated and Uncoated material is studied and compared..

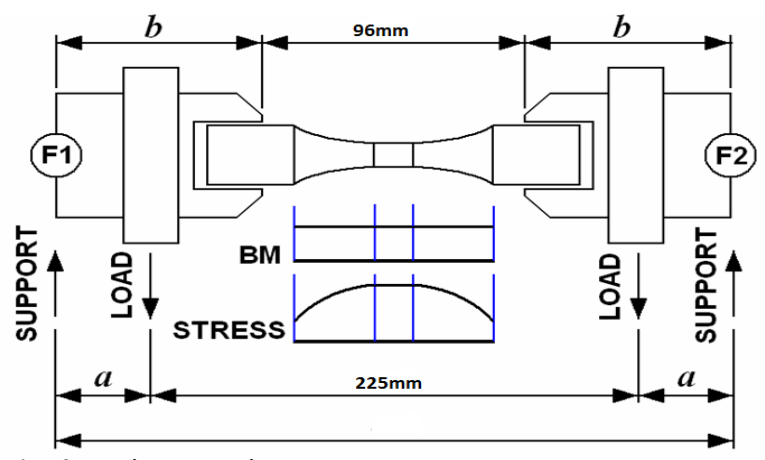

Fig. 2. Fatigue specimen

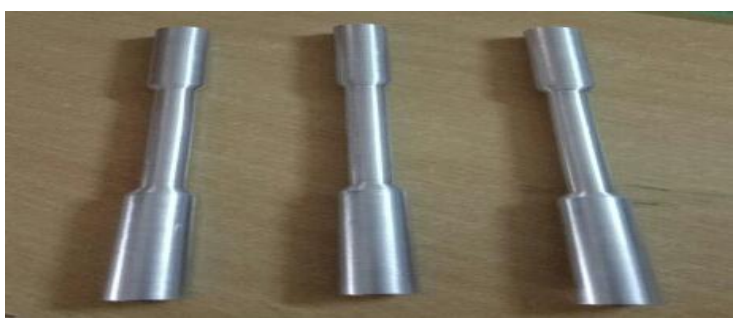

Fig. 3. Fatigue specimen samples

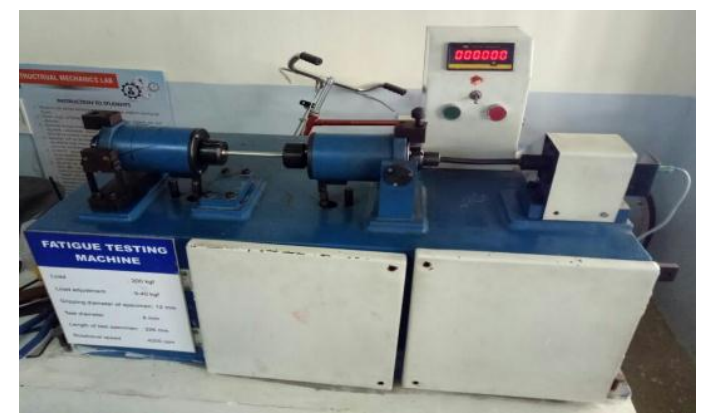

Fig. 4. Fatigue Testing Machine

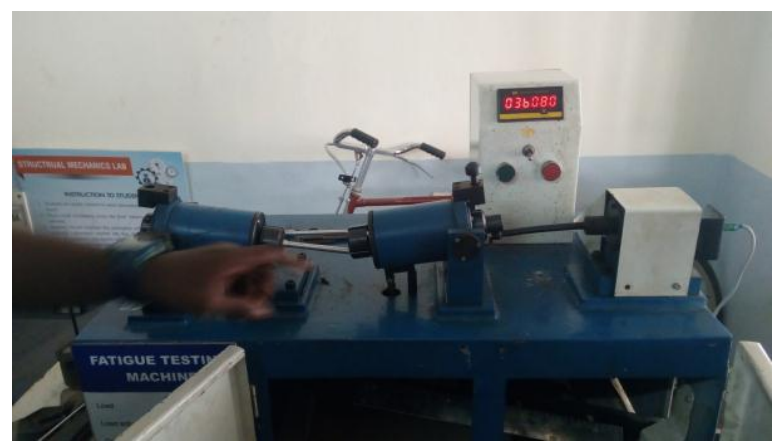

Fig 5. Fatigue specimen failed during test

\section{Fracture analysis of Failure}

Since aluminium is considered ductile, the failure is usually due to the shearing[5]. The fractrograhic study through visual and inspection gives an idea on how the material has failed. Further, the fracture is investigated through SEM analysis of the material at various scanning intensity to know about the failure mode in detail. Visual inspection shows some traces of Ductile and brittle failure of material [6].

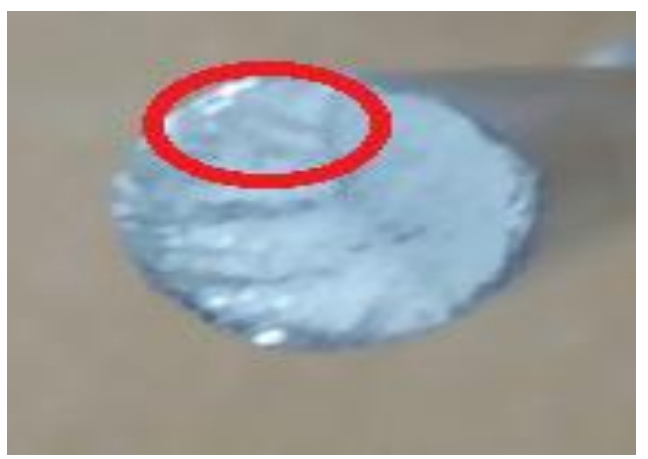

Fig. 6. Visual inspection of Specimen

The SEM image was captured to study about the failure mode of coated specimen. The SEM image shows the fracture is ductile with some traces of Brittle failure in the inner part of the material. The coated surface seems to have subjected to a shear in the surface of the material. 


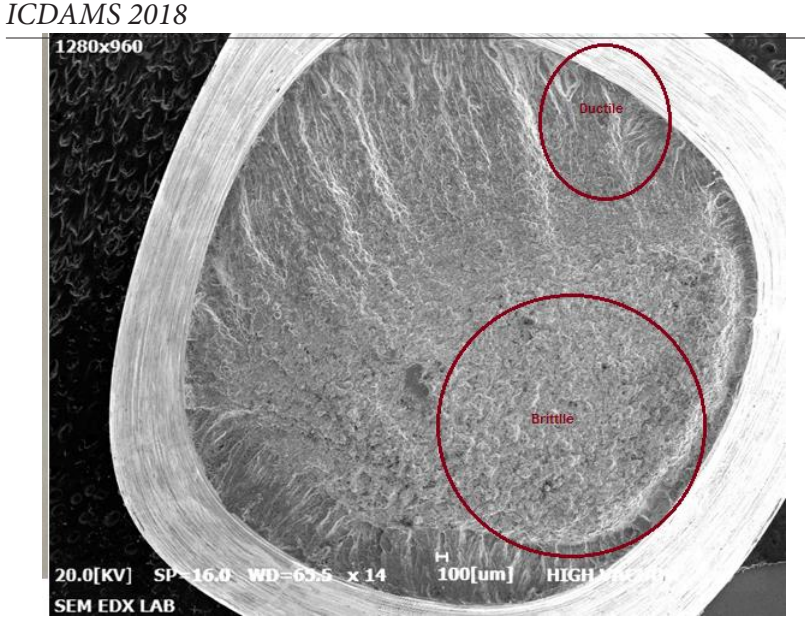

Fig. 7. SEM image showing fracture initiation

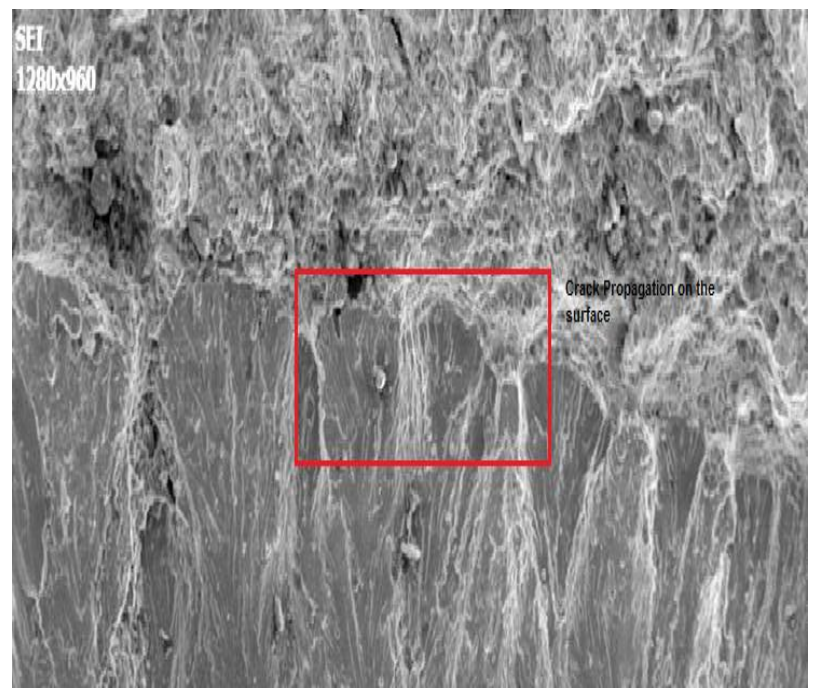

Fig. 8. Crack Initiation leading to ductile failure

The crack propagation results in failure due to cyclic loading and most of the propagation are ductile and interior failure is brittle. As the cyclic loading is increased, the crack propagation is intensified. The fracture is ductile some traces of brittleness at the core part of the material specimen. This may be due to the increase in rate at which the crack propagates at high cyclic loading.

\section{Results and Discussion}

The number of cycles for failure is studied and the increase in number cycles in noted for coated specimen to the uncoated specimen. The coated specimen shows higher number of cycles and as the load increases the number of cycles decreases but the coated specimen has a increase in life for about $14 \%$. The increase in loading has some effect on the life but the coated specimen can withstand for more time. The usage of coating has enhanced the life of the material.
Table 3. Number of Cycles at various loading.

\begin{tabular}{|c|c|c|c|c|}
\hline S.No & Specimen & $\begin{array}{c}\text { Tested at } \\
15 \mathrm{kgf}\end{array}$ & $\begin{array}{c}\text { Tested } \\
\text { at 25kgf }\end{array}$ & $\begin{array}{c}\text { Tested } \\
\text { at 35kgf }\end{array}$ \\
\hline 1 & $\begin{array}{c}\text { specimen without } \\
\text { coating }\end{array}$ & 45024 & 36080 & 31578 \\
\hline 3 & $\begin{array}{c}\text { specimen coated } \\
\text { with castor oil }\end{array}$ & 47564 & 41298 & 35674 \\
\hline
\end{tabular}

\section{References}

1. Sivasubramanian, A \& Gopal, Arunkumar. (2015). 10. 10627-10633.

2.Pedersen KO. Materials \& Design. 2011; 32:97-107.

3. Sivasubramanian, A \& Gopal, Arunkumar. (2016).

9.10.17485/ijst/2016/v9i34/100846.

4.Lin XB, Smith RA. Engineering Fracture Mechanics. $1999 ; 62: 535-53$.

5.Pedersen KO. Materials \& Design. 2011; 32:97-107

6. Arunkumar SG. Australian Journal of Basic and Applied Sciences. 2013; 7(14):281-91 